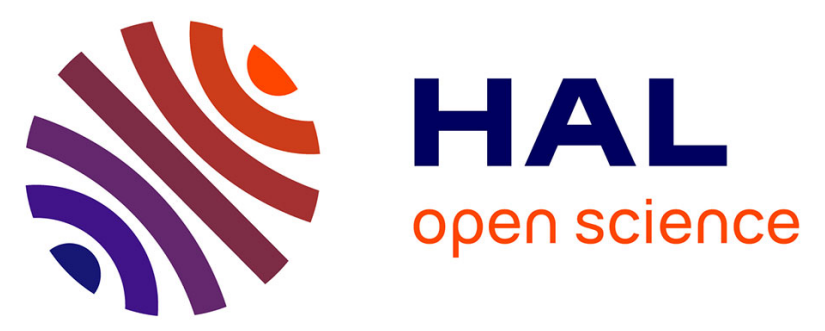

\title{
Homogenization of nonaging basic creep of cementitious materials: A multiscale modeling benchmark
}

Markus Königsberger, Túlio Honório, Julien Sanahuja, Brice Delsaute, Bernhard L.A. Pichler

\section{- To cite this version:}

Markus Königsberger, Túlio Honório, Julien Sanahuja, Brice Delsaute, Bernhard L.A. Pichler. Homogenization of nonaging basic creep of cementitious materials: A multiscale modeling benchmark. Construction and Building Materials, 2021, 290, pp.123144. 10.1016/j.conbuildmat.2021.123144 . hal-03319191

\section{HAL Id: hal-03319191 \\ https: / hal-edf.archives-ouvertes.fr/hal-03319191}

Submitted on 11 Aug 2021

HAL is a multi-disciplinary open access archive for the deposit and dissemination of scientific research documents, whether they are published or not. The documents may come from teaching and research institutions in France or abroad, or from public or private research centers.
L'archive ouverte pluridisciplinaire HAL, est destinée au dépôt et à la diffusion de documents scientifiques de niveau recherche, publiés ou non, émanant des établissements d'enseignement et de recherche français ou étrangers, des laboratoires publics ou privés. 


\title{
Homogenization of nonaging basic creep of cementitious materials: a multiscale modeling benchmark
}

\author{
Markus Königsberger ${ }^{a, b, *}$, Túlio Honório ${ }^{c}$, Julien Sanahuja $^{\mathrm{d}}$, Brice Delsaute ${ }^{\mathrm{a}}$, Bernhard L.A. Pichler \\ ${ }^{a}$ BATir Department, Université libre de Bruxelles, CP194/04, 50 avenue F.D. Roosevelt, Brussels 1050, Belgium \\ ${ }^{b}$ Institute for Mechanics of Materials and Structures, TU Wien - Vienna University of Technology, Karlsplatz 13/202, 1040 Vienna, Austria \\ ${ }^{c}$ Université Paris-Saclay, ENS Paris-Saclay, CNRS, LMT - Laboratoire de Mécanique et Technologie,61 av. du Président Wilson, 94235 Cachan \\ Cedex, France \\ ${ }^{d}$ Département Mécanique des Matériaux et des Composants, EDF RED, Site des Renardières, Avenue des Renardières, 77818 Moret-Sur-Loing \\ Cedex, France
}

\begin{abstract}
This paper presents the results of a European benchmark on multiscale creep modeling for cementitious materials, performed in the framework of the COST Action TU1404 "Towards the next generation of standards for service life of cement-based materials and structures". Three micromechanical models from three research groups have been adopted for modeling the basic non-aging creep of cementitious materials. The benchmark is based on the hypothesis that creep results only from calcium-silicate-hydrates (C-S-H) and that viscoelastic behavior of all microstructural constituents are maturity- and composition-independent. By comparing model results among themselves as well as by comparing model predictions with experimental results obtained from three different laboratories, we demonstrate that creep upscaling from micrometer-sized C-S-H to centimeter-sized macroscopic samples of cement paste, mortar, and concrete, and from minutes-long creep tests at early ages to days-long creep tests at very mature ages is indeed possible. The benchmark also highlights the importance of considering micro-anisotropy of C-S-H in terms of nonspherical shapes for C-S-H hydrates.
\end{abstract}

Keywords: cement paste, mortar, concrete, viscoelasticity, micromechanics, Calcium-Silicate-Hydrate (C-S-H), experiments, basic creep, early-age

\section{Introduction}

Herein, a benchmark regarding multiscale modeling of creep of cementitious materials is presented. It was initiated within the framework of the COST Ac5 tion TU1404 "Towards the next generation of standards for service life of cement-based materials and structures" [1]. The benchmark refers to nonaging creep properties of cement paste, mortars, and concretes, both at early and mature material ages. Innovative creep tests performed at three laboratories on seven different mixes constitute the experimental basis for the benchmark. This study complements the multiscale modeling benchmark focused on the early-age evolution of the stiffness and strength of cementitious materials [2].

\footnotetext{
${ }^{*}$ Corresponding author

Email address: markus . koenigsberger@tuwien. ac . at (Markus Königsberger)
}

15 Multiscale micromechanics models for homogenization of mechanical properties of cementitious materials [3, 4, 5, 6, 7, 8, 9] are applied for predicting the creep properties of young and mature cementitious materials. These models are adopted by the three par20 ticipating research groups and applied to quantify the evolution of the non-aging creep behavior of cement paste, mortar, and concrete-from very early to very mature ages. Recently, it was shown that the hydration products, which form during the physico-chemical processes of cement hydration, exhibit intrinsic creep properties at the micrometer scale [10], irrespective of maturity or composition of the material. Following this hypothesis, the creep behavior of the hydrates will be characterized by downscaling minutes-long creep tests so performed on young cement paste. The such-obtained intrinsic hydrate creep function is thereafter used for bridging length and time scales. In more detail, we first aim for predicting creep properties at larger mate- 
rial scales, i.e. at the mortar and concrete scales. More35 over, we aim for predicting creep properties at larger time scales, i.e. for very mature materials (with ages up to several years) and/or loading durations of several days. The required experimental data are obtained from three different concrete laboratories and include novel creep test results stemming from the experimental stage of the COST Action TU1404 [1].

The article is structured as follows: Section 2 refers to the experimental data. Section 3 is devoted to a brief description of three complementary multiscale model45 ing approaches. Section 4 refers to the actual benchmark. At first, the strategy is described. Thereafter, a top-down identification approach is used to quantify the creep constants of the viscoelastic hydrates, based on the results of three-minutes creep tests of hydrating cement pastes. After that, all three models are used to predict the short-term creep behavior of hydrating mortars and concretes, as well as the longer-term creep behavior of a very mature cement paste. In Section 6 , the paper is closed with conclusions obtained from the comparison 55 of the three independent creep models and their performance.

\section{Experimental data}

The experimental data included in the benchmark were obtained from hourly-repeated minutes-long creep 110 tests on six different hydrating cementitious materials, including one concrete representative of nuclear containment buildings, as well as from one 30-days-long creep test of a very mature cement paste, see also Table 1. Direct uniaxial compression experiments were 65 performed. Every single test was organized in two phases: the application of the loading, referred to as the initial loading ramp, and the actual creep tests during which the loading was kept constant, referred to as the load plateau. Load cells measured the applied compres70 sive forces $F$, as a function of time $t$. Dividing $F(t)$ by the cross-sectional area $A_{c}$ of the tested specimen, delivers the time-evolution of the prescribed compressive normal stress

$$
\sigma(t)=\frac{F(t)}{A_{c}} .
$$

The resulting deformation of the specimens, i.e. the time-evolution of the compressive normal strain, $\varepsilon^{\exp }(t)$, was measured with a suitable equipment.

All creep tests of the benchmark refer to a practically constant microstructure of the tested material. This is 80 the rationale for the expression "nonaging" creep tests. In addition, the imposed compressive loading was always smaller than $20 \%$ of the compressive strength of 130 the material at the time of testing. Thus, the specimens remained virtually undamaged and testing was 5 carried out in the linear creep regime [14]. Notably, given the short repeated creep tests with strains $\varepsilon^{\exp (t)}$ refer to basic creep strains, because isothermal testing was performed (no thermal strains), the specimens were sealed (no drying shrinkage nor drying creep), and the o microstructure was virtually constant during testing (no autogeneous shrinkage).

Repeated minutes-long basic creep tests are wellsuited for efficiently characterizing the hardeninginduced evolution of nonaging creep properties [11, 12, 95 15, 16, 17, 18]. During minutes-long loading, the microstructure of the material remains virtually the same, because the chemical reaction between cement and water does not proceed significantly. The ultra-short creep tests are repeated hourly while the specimen remains installed in the loading apparatus. Basic creep strains during repeated ultra-short creep tests are shown to be reversible [11, 16, 18]. Irreversible strains, as observed in long-term creep tests during the maturation, are absent, see e.g. Fig. 18 of Ref. [11]. Moreover, results from repeated creep tests with minutes-long loading periods alternating with periods of virtually no loading for almost one hour are shown to be very similar to results from single creep tests on previously unloaded samples at the corresponding age [16, 18].

The benchmark is particularly focused on creep strains $\varepsilon_{v}^{\exp }(t)$. Creep strains can be obtained from the measured total strains $\varepsilon^{\exp }(t)$ by subtracting the elastic strains $\varepsilon_{e l}^{\exp }(t)$ :

$$
\varepsilon_{v}^{\exp }(t)=\varepsilon^{\exp }(t)-\varepsilon_{e l}^{\exp }(t) .
$$

15 The elastic strains, in turn, can be quantified based on knowledge regarding the applied uniaxial stresses $\sigma(t)$, see Eq. (1), and the modulus of elasticity $E$, following Hooke's law:

$$
\varepsilon_{e l}^{\exp }(t)=\frac{\sigma(t)}{E} .
$$

20 Eqs. (2) and (3) underscore that accurate quantification of the modulus of elasticity is of considerable importance for the accurate quantification of creep strains, in particular since elastic deformations typically outweigh the viscous ones by one order of magnitude.

\subsection{Creep tests performed at Vienna University of Technology (TUW)}

The benchmark involves experimental data from five early-age testing campaigns carried out at TUW (Table 11. The tested materials were produced with an ordinary Portland cement of type CEM I 42.5 N, distilled 
Table 1: Initial compositions of the analyzed cementitious materials, testing ages, and durations of the creep tests; $w / c, s / c$, and $a / c$ refer to the initial water-to-cement, sand-to-cement, and aggregate-to-cement mass ratios

\begin{tabular}{|c|c|c|c|c|c|c|c|}
\hline & Mix 1 & Mix 2 & Mix 3 & Mix 4 & Mix 5 & Mix 6 & Mix 7 \\
\hline & $\begin{array}{l}\text { cement } \\
\text { paste }\end{array}$ & $\begin{array}{l}\text { cement } \\
\text { paste }\end{array}$ & $\begin{array}{l}\text { cement } \\
\text { paste }\end{array}$ & $\begin{array}{l}\text { laboratory } \\
\text { mortar }\end{array}$ & $\begin{array}{l}\text { laboratory } \\
\text { concrete }\end{array}$ & $\begin{array}{l}\text { VeRCoRs } \\
\text { concrete }\end{array}$ & $\begin{array}{c}\text { cement } \\
\text { paste }\end{array}$ \\
\hline$w / c$ & 0.42 & 0.45 & 0.50 & $0.50^{\#}$ & $0.50^{\#}$ & $0.52^{*}$ & 0.50 \\
\hline$s / c$ & 0 & 0 & 0 & 3 & 0 & 3.109 & 0 \\
\hline$a / c$ & 0 & 0 & 0 & 0 & 3 & 2.594 & 0 \\
\hline laboratory & TUW & TUW & TUW & TUW & TUW & ULB & NRC \\
\hline material ages at testing & $24-168 h$ & $24-168 h$ & $24-168 h$ & $24-168 h$ & $24-168 h$ & $14 \mathrm{~h}-94 \mathrm{~h}^{\dagger}$ & 30 years \\
\hline test duration & $3 \min$ & $3 \min$ & $3 \min$ & $3 \min$ & $3 \min$ & $5 \min$ & 30 days \\
\hline reference & [11] & [11] & [11] & [12] & [12] & novel & [13] \\
\hline used for & \multicolumn{3}{|c|}{ calibration of the models } & \multicolumn{4}{|c|}{ assessment of predictive capabilities } \\
\hline
\end{tabular}

$\dagger$ creep tests were performed until material ages of $318 \mathrm{~h}$, but heat release measurements are considered to be reliable for $94 \mathrm{~h}$ only

water, and quartz sand/aggregates. Mixes 1, 2, and 3 refer to cement pastes with initial water-to-cement mass ratios $w / c$ amounting to $0.42,0.45$, and 0.50 , respectively. The experimental data are taken from [11]. Mix 4 refers to a laboratory mortar, produced with $w / c=0.50$ and initial sand-to-cement mass ratio $s / c$ amounting to 3.0. Mix 5 refers to a laboratory concrete, produced with $w / c=0.50$ and initial aggregate-to-cement mass ratio $a / c$ amounting to 3.0. Notably, sand and aggregates were oven-dried. The experimental data are taken from [12]. A degree of hydration was assigned to every three-minutes creep test, based on quasi-isothermal differential calorimetry measured for all three cement paste mixes, and considered equal for the corresponding mortar and concrete mixes with similar $w / c$ ratio [11].

As regards test evaluation, the unloading modulus was used as a first estimate of the modulus of elasticity. This allowed for extracting the creep strains from the measured total strains, see Eqs. (1)-3) and [11, 12] The obtained creep strains were unrealistic, because unphysical tensile creep strains developed right after the beginning of the loading phase, a phenomenon labelled "tensile undershooting", see Fig. 7 (a) in [11]. In other words, the elastic strains evaluated based on the unloading modulus were larger (in absolute numbers) than the measured total strains right after the start of the loading. Thus, the estimate of the modulus of elasticity was gradually increased, resulting in gradually decreasing (absolute values of) elastic strains, until the tensile creep strains had disappeared entirely. The obtained final es- timate of the modulus of elasticity was (i) typically by $2-5 \%$ larger than the unloading modulus, and (ii) practically equal to the modulus of elasticity quantified based on ultrasonic pulse velocity measurements of longitudinal and shear waves [11].

\subsection{Creep tests performed at Université libre de Brux- elles (ULB)}

Five-minute-long basic creep tests were carried out 70 at early material ages at ULB, in order to characterize the "VeRCoRs" 1 concrete within the framework of the COST Action TU1404, see Mix 6 in Table 1 . The corresponding test data are original contributions of this paper. Therefore, they are described in more detail.

Concrete was produced using CEM I $52.5 \mathrm{~N} \mathrm{CE}$ CP2 NF. It consisted of $96 \%$ (weight) ordinary Portland cement and 4\% limestone filler. The cement consisted of $68,10,9,7,2.2$, and $3.3 \%$ (weight) of $\mathrm{C}_{3} \mathrm{~S}, \mathrm{C}_{2} \mathrm{~S}, \mathrm{C}_{3} \mathrm{~A}, \mathrm{C}_{4} \mathrm{AF}, \mathrm{MgO}$, and Gypsum, respectively. Oven-dried siliceous sand from Sandrancourt in France and water-saturated siliceous-calcareous gravel in size classes 4/11 mm and 8/16 mm were used. Superplasticizer SIKAPLAST techno 80 was added to the mixing water. As for the production of $1 \mathrm{~m}^{3}$ of concrete, the

\footnotetext{
1 "VeRCoRs", acronym of "Verification Réaliste du COnfinement des RéacteurS", is a 1/3 scale mock-up [19] of a nuclear power plant containment building, built at EDF lab, to improve both knowledge on and modeling of containment buildings ageing. The structure is heavily instrumented [20] and its concrete is the subject of many studies, see for example [21] regarding creep.
} 
following mix proportions were used: $320 \mathrm{~kg}$ of binder, $830 \mathrm{~kg}$ of dry sand, $995 \mathrm{~kg}$ of water-saturated aggregates, $2.4 \mathrm{~kg}$ superplasticizer, and $171 \mathrm{~kg}$ of extra water, see also [17].

The evolution of the degree of hydration $\xi$ was quantified based on isothermal calorimetry tests, performed inside a 8-channel TAM Air micro-calorimeter at $20^{\circ} \mathrm{C}$. The tests delivered the cumulatively released heat per unit mass of the binder, $Q(t)$, see Fig. 11. Accounting for ${ }_{225}$

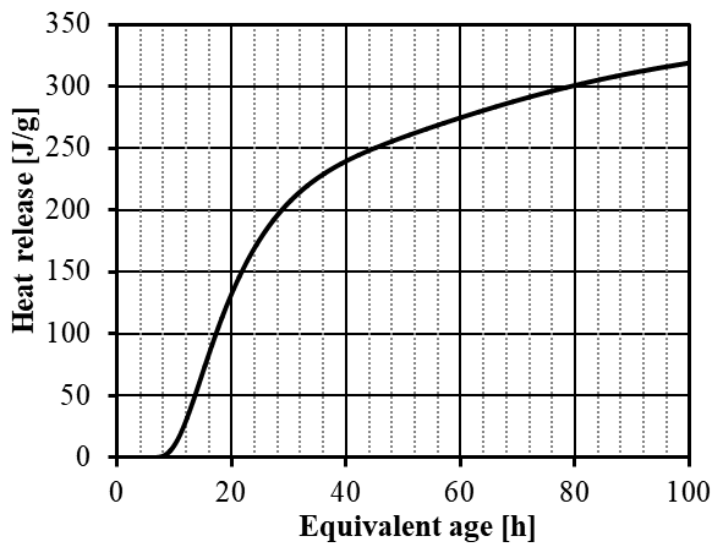

Figure 1: Calorimetry-based cumulative heat release $Q$ for VeRCoRs concrete (Mix 6) as function of the age of the material

a ultimate heat of the binder amounting to $510 \mathrm{~J} / \mathrm{g}$, see Neville [22] for the enthalpies of the individual clinker phases, the degree of hydration $\xi$ is quantified as

$$
\xi(t)=\frac{Q(t)}{510 \mathrm{~J} / \mathrm{g}} .
$$

Uncertainties of $\xi$ regarding the determination of the ultimate heat and the calorimetry measurements remained unconsidered. As for mechanical testing, a cylindrical specimen with a diameter of $97 \mathrm{~mm}$ and a height ${ }_{250}$ of $550 \mathrm{~mm}$ was produced. After casting, the specimen was sealed and placed in an air-conditioned chamber at $20^{\circ} \mathrm{C}$ and a relative humidity of $90 \%$. The setting process was monitored based on ultrasonic longitudinal and shear waves which were sent through the specimen [23]. 255 Shortly after the final setting, $12.1 \mathrm{~h}$ after production, the sample was demolded, ground on both circular end faces, and sealed by means two self-adhesive aluminum sheets.

The tests were carried out in a Walter+Bay LFMZ 260 $100 \mathrm{kN}$ electromechanical testing machine, located in an room conditioned to a temperature of $20^{\circ} \mathrm{C}$ and a relative humidity of $50 \%$. The length-changes of the specimen were measured in its central part, which is virtually free of undesired shear stresses resulting from 265

friction in the interface between the load platens and the specimen, see Fig. 2 of [24]. To this end, two metal rings were fixed to the specimen, using three anchorages with elastic blades per ring [25]. The initial distance between the rings was equal to $350 \mathrm{~mm}$. Three displacement sensors of type Solartron, with a maximum stroke of $0.5 \mathrm{~mm}$, were equally distributed around the specimen. They measured the changes of distance between the two metal rings. The three measured length changes, $\Delta \ell_{i}$ with $i=1,2,3$, were averaged and divided by the measurement length, in order to quantify the total axial strain of the specimen

$$
\varepsilon^{\exp }(t)=\frac{1}{350 \mathrm{~mm}} \sum_{i=1}^{3} \frac{\Delta \ell_{i}(t)}{3} .
$$

230 40 kept constant for 5 min. Subsequently, the specimens
were unloaded within 10 seconds. In order to maintain contact between the load platens and the specimen, a small permanent stress amounting to $0.041 \mathrm{MPa}$ was imposed on the sample between two successive tests. Full details on the test protocol can be found in Delsaute and Staquet [18].

As regards test evaluation, measured total strains $\varepsilon^{\exp }(t)$ are decomposed into elastic and viscous strains according to (2). The elastic modulus was estimated from the slope of the central $60 \%$ of the stress-strain diagram within the loading and unloading branches, respectively, [26, 27]. The average of both loading and unloading modulus for a specific creep test is considered as estimate of the elastic modulus. Notably, loading and unloading moduli are almost identical, and the evolution of the moduli is in agreement with results obtained by the laboratory of Électricité de France (EDF), 28 days after production [17], see Fig. 2] The material's actual elastic modulus $E$ is most likely a few percent larger than the loading/unloading modulus due to shortterm creep strains occurring during loading/unloading [11]. Elastic strains following from (3), evaluated for the loading/unloading moduli, thus very likely overestimate the real elastic strains such that the viscous strains 
according to Eq. (2) might be significantly underestimated.

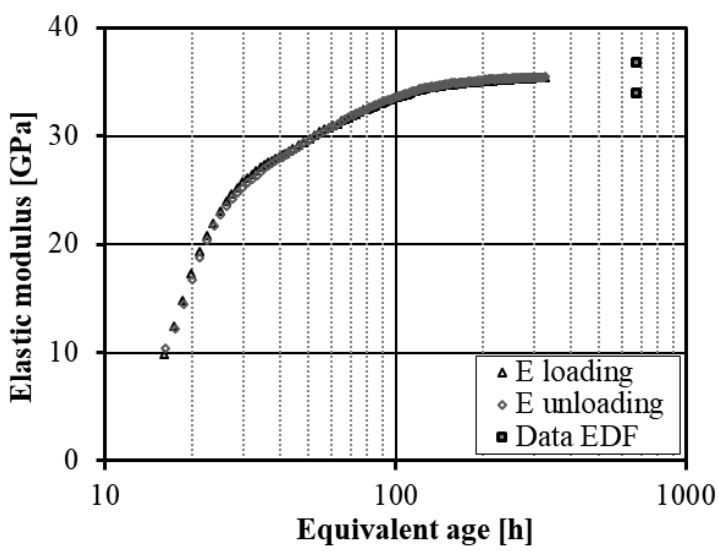

Figure 2: Evolution of loading and unloading moduli of VeRCoRs concrete (Mix 6), determined from hourly-repeated 5-min creep testing at early ages, and 28-days-stiffness values determined by EDF [17]

As for a condensed representation of the experimental data, the resulting viscous creep strains $\varepsilon_{v}^{\exp }(t)$ are represented by means of the viscous creep function $J_{v}^{\exp }$ as

$$
\varepsilon_{v}^{\exp }(t)=\int_{-\infty}^{t} J_{v}^{\exp }(t-\tau) \dot{\sigma}(\tau) \mathrm{d} \tau,
$$

with logarithmic viscous creep function $J_{v}^{\exp }$ reading as [28]

$$
J_{v}^{\exp }(t-\tau)=\frac{A}{E} \ln \left[1+(\mathrm{e}-1)\left(\frac{t-\tau}{t_{c}}\right)^{K}\right] .
$$

In Eq. (7), parameter $A$ is the amplitude of the creep coefficient after 5 minutes of loading and parameter $K$ is related to the kinetics of the basic creep, and $t_{c}=$ $5 \mathrm{~min}$ is the reference time. The amplitude parameter $A$ significantly decreases from 0.24 at the first creep test at an age of $14 \mathrm{~h}$ to 0.05 for the last creep test at an age of $318 \mathrm{~h}$, while the kinetic parameter decreases from a value of 0.5 at early age to 0.4 at mature ages, see Fig. 3

\subsection{Creep test performed at the Canadian National Re- ${ }^{315}$ search Council (NRC)}

Tamtsia and Beaudoin [13] performed a 30-days creep test of a cement paste with $w / c=0.5$, which was stored for 30-years under water, see Mix 7 in Table 1 Although the characterized material was still not per- 320 fectly inert, the reaction kinetics between cement and

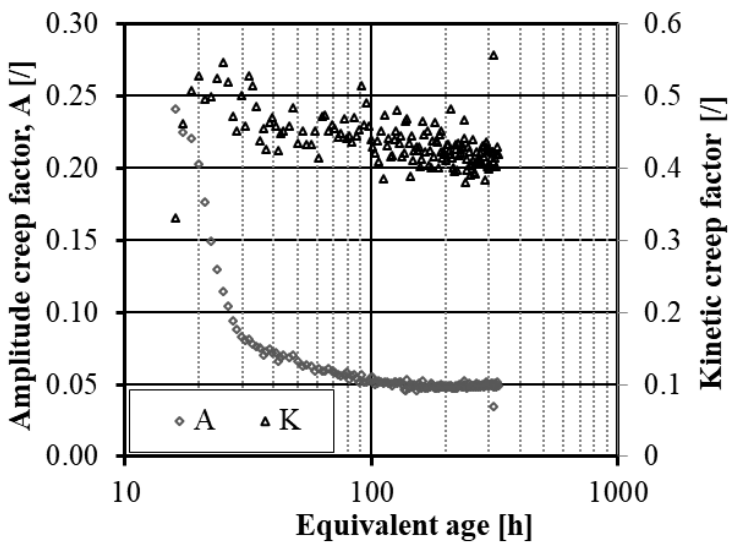

Figure 3: Evolution of the creep parameters $A$ and $K$ for VeRCoRs concrete (Mix 6), determined from hourly-repeated 5-min creep testing at early ages

water had decayed so significantly, that the microstructure of the material was in good approximation constant throughout the test. Thus, also this test refers to nonaging creep properties.

The degree of hydration of the material is estimated as follows. Using $w / c=0.50$ and the initial Blaine fineness of $340 \mathrm{~m}^{2} / \mathrm{kg}$ [29] as input, the empirical law by Lin and Meyer [30] suggests that the final degree of hydration amounts to $87 \%$.

\section{Multiscale models}

Three different multiscale models participate in the benchmark. They are based on methods of continuum micromechanics [31]. The models account for two key features of the three-dimensional microstructure of cementitious materials:

Material organogram: Each model is based on a specific representation of the hierarchical organization of cementitious materials, see Fig. 4. The models introduce three to five different scales of observations. They range from the macroscale of concrete down to microscopic and/or nanoscopic scales of hydration products and pores.

Number and type of material constituents: At each scale of observation, the microstructures are envisaged to consist of a specific number of quasihomogeneous constituents. They are referred to as "material phases".

All three models account for four key features of the material phases. Two of them are of qualitative nature, the other two are of quantitative nature. 
Phase shape and orientation: Each material phase is modeled based on an ellipsoidal shape and nonpreferred orientation. In more detail, the involved approaches include spherical phases, where orientation does not matter, as well as prolate (needlelike) or oblate (lens-like) spheroidal phases which are modeled to be isotropically oriented in space.

Phase arrangement and interaction: If the material phases, forming the microstructure at a specific scale of observation, exhibit direct mutual interaction, the self-consistent scheme will be used for homogenization [32, 33]. If the material phases form a matrix-inclusion composite, Mori-TanakaBenveniste scheme will be used for homogenization [34, 35]. If coated spheres are envisaged, creep homogenization is performed according to Ref. [36].

Hydration-induced evolution of phase volumes:

The early-age evolution of macroscopic viscoelastic properties of cementitious materials is explained based on evolving volume fractions. The models account for the consumption of cement and water and the associated production of hydrates.

Material constants: All material phases are considered to be isotropic. Their material behavior is either modeled as being linear elastic or linearviscoelastic. Material constants are assigned to the smallest quasi-homogeneous constituents, rather than material parameters.

As for the linear-elastic material phases (index $p$ ), generalized Hooke's law describes the relation between average phase stresses $\sigma_{p}$ and average phase strains $\boldsymbol{\varepsilon}_{p}$ :

$$
\boldsymbol{\sigma}_{p}(t)=\mathbb{C}_{p}: \boldsymbol{\varepsilon}_{p}(t) .
$$

The time-independent isotropic elastic stiffness tensors $\mathbb{C}_{p}$ read as

$$
\mathbb{C}_{p}=3 k_{p} \mathbb{I}_{v o l}+2 \mu_{i} \mathbb{I}_{d e v},
$$

where $k_{p}$ and $\mu_{p}$ stand for the bulk and the shear moduli of phase $p$, and $\mathbb{I}_{v o l}$ and $\mathbb{I}_{d e v}$ for the volumetric and deviatoric parts of the symmetric fourth-order identity tensor.

As for the viscoelastic hydrate phases (index $h$ ), the average stresses $\sigma_{h}$ are related to the average strains $\boldsymbol{\varepsilon}_{h}$ based on the following convolution integral, expressing Boltzmann's superposition principle [38]:

$$
\boldsymbol{\varepsilon}_{h}(t)=\int_{-\infty}^{t} \mathrm{~J}_{h}(t-\tau): \dot{\boldsymbol{\sigma}}_{h}(\tau) \mathrm{d} \tau .
$$

The time-dependent creep tensor functions $\mathbb{J}_{h}(t-\tau)$ are isotropic. They contain a time-independent elastic part $\mathbb{C}_{h}^{-1}$ and a time-dependent viscous part $\mathrm{J}_{v, h}(t-\tau)$ :

$$
\mathrm{J}_{h}(t-\tau)=\mathbb{C}_{h}^{-1}+\mathrm{J}_{v, h}(t-\tau) .
$$

The three models participating in the benchmark are based on a deviatoric tensorial creep tensor function, reading as

$$
\mathrm{J}_{v, h}(t-\tau)=\frac{\mathbb{I}_{d e v}}{2 \mu_{c, h}}\left(\frac{t-\tau}{t_{r e f}}\right)^{\beta_{h}}
$$

whereby $t_{r e f}=1 \mathrm{~d}=86400 \mathrm{~s}$ denotes the constant reference time. The two material constants $\mu_{c, h}$ and $\beta_{h}$ stand for the shear creep modulus $\mu_{c, h}$ and the powerlaw creep exponent $\beta_{h}$.

\subsection{Model $3 N$}

The multiscale Model 3N is based on a 3 -scale representation of concrete and on needle-shaped hydrates, hence the acronym " $3 \mathrm{~N}$ ". This representation was introduced in [5] in the context of upscaling stiffness and strength of hydrating cement pastes, and it was applied to creep homogenization in [7]. According to Model 3N, the microstructure of concrete and mortar consists of a matrix made of cement paste and spherical inclusions representing sand and aggregates. The microstructure of cement paste consists of a matrix referred to as "hydrate foam" and spherical inclusions representing clinker grains. The microstructure of the hydrate foam consists of a polycrystalline arrangement of spherical capillary porosity and hydrate-gel needles which are isotropically oriented in space. For the sake of simplicity, the aspect ratio of the needles is set equal to infinity [5]. The microstructure of the hydrate-gel needles is not resolved explicitly, but it would contain nanoscopic solid hydrates and gel pores.

The hydration-induced evolution of the volume fractions of clinker, hydrates, and pores is quantified based on Powers' model [39]. The latter expresses the volume fractions as a function of the degree of hydration $\xi$ and the water-to-cement ratio $w / c$. Accordingly, the cement paste-related phase volume fractions of clinker $f_{c l i n}^{c p}$, of water $f_{\mathrm{H}_{2} \mathrm{O}}^{c p}$, of hydrates $f_{\text {hyd }}^{c p}$, and of self-desiccation- 


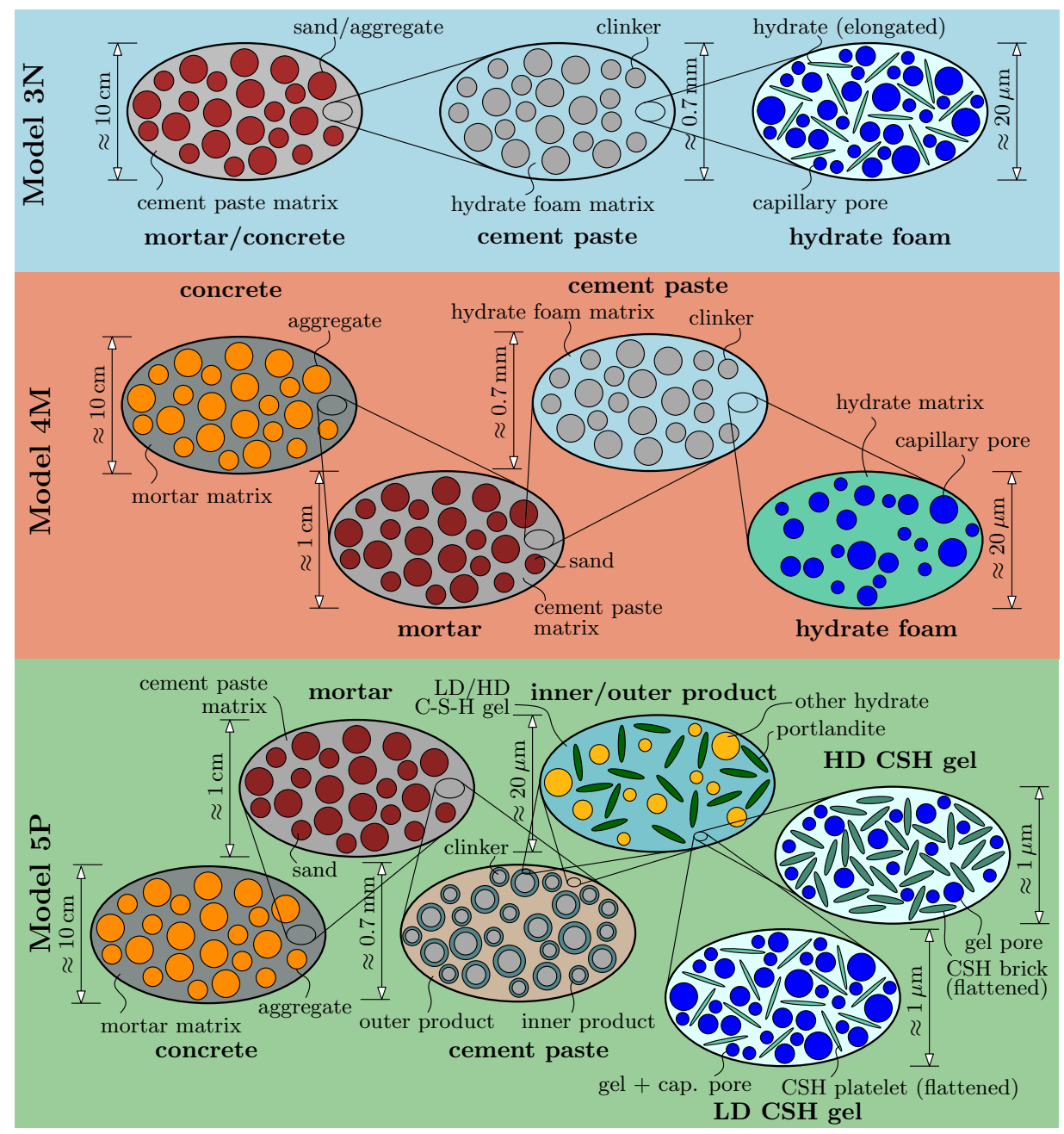

Figure 4: Material organograms representing the envisaged hierarchical organization of concrete: (a) Model 3N: 3-scale representation including needle-shaped hydrates after Pichler and Hellmich [5], Königsberger et al. [7]; (b) Model 4M: simplified 4-scale representation including a hydrate matrix after Honorio et al. [6]; (c) Model 5P: 5-scale representation including platelet-shaped hydrates, multi-hydrate extension of Sanahuja et al. [3] 37]; the two-dimensional sketches illustrate qualitative properties of three-dimensional representative volume elements 
induced air porosity $f_{\text {air }}^{c p}$ read as [5]:

$$
\begin{aligned}
f_{\text {clin }}^{c p} & =\frac{20(1-\xi)}{20+63 w / c} \geq 0, \\
f_{H_{2} O}^{c p} & =\frac{63(w / c-0.42 \xi)}{20+63 w / c} \geq 0, \\
f_{\text {hyd }}^{c p} & =\frac{43.15 \xi}{20+63 w / c}, \\
f_{\text {air }}^{c p} & =\frac{3.31 \xi}{20+63 w / c} .
\end{aligned}
$$

400

Elastic phase properties of all phases are given in Table 2 . Only the hydrate phase is considered to be viscoelastic, with viscous creep tensor function according to Eq. (12).

Table 2: Isotropic elastic phase properties: $k_{i} \mid \mu_{i}$ in GPa

\begin{tabular}{lccc}
\hline Phase & Model 3N & Model 4M & Model 5P \\
\hline Hydrates & $18.7 \mid 11.8$ & $18.7 \mid 8.5$ & - \\
C-S-H & - & - & $25.2 \mid 15.9$ \\
Portlandite & - & - & $35.6 \mid 15.0$ \\
Other Hyd. & - & - & $33.3 \mid 15.4$ \\
Pores & $0 \mid 0$ & $0 \mid 0$ & $0 \mid 0$ \\
Clinker & $117 \mid 53.8$ & $113 \mid 51.9$ & $113 \mid 51.9$ \\
Sand & $37.8 \mid 44.3$ & $36.1 \mid 27.1$ & $36.1 \mid 27.1$ \\
Aggregates & $37.8 \mid 44.3$ & $36.1 \mid 27.1$ & $36.1 \mid 27.1$ \\
\hline
\end{tabular}

Creep homogenization is based on the correspondence principle. The time-dependent problem is transformed to the Laplace-Carson space, see [10] for computational details. There, the upscaling challenge represents itself as a sequence of quasi-elastic homogenization problems. The pointwisely-computed solution is finally back-transformed to the regular time space.

\subsection{Model $4 M$}

The multiscale Model $4 \mathrm{M}$ is based on a $\underline{4}$-scale representation of concrete with a hydrate matrix, hence the acronym " $4 \mathrm{M}$ ". This representation has been used to upscale thermal [40] and electromagnetic [41, 42] properties of cement-based materials and is a simplified version of the modeling approach presented in Ref. [6]. According to Model 4M, the microstructure of concrete 470 consists of a matrix made of mortar and spherical inclusions representing aggregates. The microstructure of mortar consists of a matrix made of cement paste and spherical inclusions representing sand. The microstructure of cement paste consists of a hydrate-foam ma- 475 trix and spherical inclusions representing clinker grains.

The microstructure of the hydrate foam consists of a hydrate matrix and spherical inclusions representing capillary pores. The microstructure of the hydrate matrix is not resolved explicitly, but it would contain nanoscopic 430 solid hydrates and gel pores.

By analogy to Model 3N, the hydration-induced evolution of the volume fractions of clinker, hydrates, and pores is quantified based on Powers' model [39]. Elastic phase properties of clinker, sand, and aggregates are Table 2 The intrinsic hydrate stiffness is backidentified from the measured Young's modulus evolutions of Mix 1-3. The creep tensor function of the hydrate matrix is considered to be deviatoric, see Eq. (12).

Creep homogenization is performed using Mori${ }_{440}$ Tanaka estimates extended to aging linear viscoelasticity [43], using a correspondence principle based on Volterra integral operators. The solution is made in time space using numerical integration of Volterra operators.

\subsection{Model $5 P$}

The multiscale Model 5P is based on a 5-scale representation of concrete and on platelet-shaped hydrates, hence the acronym " $5 \mathrm{P}$ ". This representation is a multihydrate extension of the modeling approach presented in [3]. According to Model 5P, the microstructure of concrete consists of a matrix made of mortar and spherical inclusions representing aggregates. The microstructure of mortar consists of a matrix made of cement paste and spherical inclusions representing sand. The microstructure of cement paste consists of a matrix made of "outer products" and spherical inclusions representing clinker grains covered by "inner products". The microstructure of inner/outer products consists of a matrix made of high-density/low-density C-S-H-gel, oblate portlandite inclusions (with an aspect ratio amounting to 0.1), and spherical inclusions representing other hydrates such as AFm, AFt, Calcium Aluminate, Hydrogarnet, etc. The microstructure of the two types of C-S-H gels consists of a polycrystalline arrangement of spherical pores and oblate solid hydrates which are isotropically oriented in space. The low-density C-S-H gel consists of gel pores, capillary pores, and solid C-S-H platelets with an aspect ratio amounting to $10^{-4}$ (resulting from fitting the Young's moduli of mixes 1-3). The high-density C-S-H gel consists of $30 \%$ (volume) gel pores and $70 \%$ (volume) solid C-S-H bricks with an aspect ratio amounting to 0.12 [3].

The hydration-induced evolution of the volume fractions of the constituents of cement paste is quantified as a function of $w / c$ and $\xi$, based on EDF's $\operatorname{Vi}(C A)_{2} T$ v2 code. Hydration of clinker is simulated through simplified kinetics approaches from Avrami [44] and Fuji, 
Kondo [45]. Stoichiometry is enforced through commonly used simplified hydration reactions of clinker components $\mathrm{C}_{3} \mathrm{~S}, \mathrm{C}_{2} \mathrm{~S}, \mathrm{C}_{3} \mathrm{~A}, \mathrm{C}_{4} \mathrm{AF}$. Details regarding found in Refs. 46,37 . The hydration module yields the evolution of volume fractions of the chemical constituents of cement paste. In order to distinguish between inner and outer hydrates, the Tennis-Jennings model [47] is used. Portlandite and other hydrates are assumed to follow the same inner/outer repartition as C$\mathrm{S}-\mathrm{H}$. As this benchmark application provides the global degree of hydration $\xi$, the latter is used instead of time to retrieve the amounts of the phases of cement paste from $\mathrm{Vi}(\mathrm{CA})_{2} \mathrm{~T}$ hydration simulation results.

C-S-H bricks and platelets are considered to exhibit ${ }_{540}$ a deviatoric creep tensor function according to Eq. (12). The creep function (12) is a simplification of the micromechanical model of C-S-H gel creep [4] where creep is assumed to stem from viscous sliding of C-S-H sheets inside bricks. Regarding these bricks, Sanahuja and Dormieux [4] considered a transverse isotropic compliance tensor function (whose creep part is non zero only for shear stresses activating sheets sliding), while in the current model the latter is isotropic (and the creep part is deviatoric). Elastic phase properties are given in Table 2, the Young's modulus of C-S-H bricks and platelets is identified from experimental Young's modulus results on mixes 1-3, while Poisson's ratio is 550 taken as 0.24 .

Creep homogenization is performed by the upscaling module of $\mathrm{Vi}(\mathrm{CA})_{2} \mathrm{~T}$ [37], using the correspondence principle, see above. Finally, the Laplace-Carson transform is numerically inverted by the Stehfest algorithm 555 [48].

\section{The benchmark}

The three multiscale models are used to model the viscoelastic properties of cement pastes, mortars, and concretes by means of homogenization of the viscoelas-

515 tic properties of the material constituents. The mate- 560 rial phases are considered to exhibit universal viscoelastic properties, i.e. the elastic and creep behavior at microstructural level neither changes when composition of the material is modified, nor does it change during the hydration. The universality of viscoelastic properties is applicable to hydrates which precipitate at early and mature ages, as long as the hydrates are well-saturated (e.g. by means of water-curing), as demonstrated by previous multiscale modeling at the cement paste scale [10]. Herein this hypothesis is revisited and its verification at mortar and concrete scales is tested. Therefore, the creep constants at the hydrate scale are first identified by means of top-down identification based on cement paste Mixes 1-3. Thereafter, the short-term macroscopic creep of mortar and concrete Mixes 4-6 as well as the longer-term creep of cement paste Mix 7 is predicted and the model performance is assessed.

\subsection{Identification of $C$-S-H creep behavior}

To quantify the creep behavior of C-S-H hydrates, the creep test results of cement paste mixes tested at TUW (Mixes 1-3) are downscaled to the hydrates, as shortly summarized next. The loading in these creep tests is applied at virtually constant stress rate $\dot{\sigma}^{*}=2 \mathrm{MPa} / \mathrm{s}$. After reaching the plateau stress $\sigma^{*}$ at time $t^{*}$, it is kept constant, yielding a bilinear function for the stress rates as

$$
\dot{\sigma}= \begin{cases}\dot{\sigma}^{*}=\text { const } & \forall t<t^{*}, \\ 0 & \forall t \geq t^{*} .\end{cases}
$$

Model-predicted macroscopic viscous strains $\varepsilon_{v}^{\text {mod }}$ read as

$$
\varepsilon_{v}^{\bmod }(t)=\int_{0}^{t} J_{v}(t-\tau) \dot{\sigma} \mathrm{d} \tau,
$$

with $J_{v}$ denoting the viscous part of the 1111component of the homogenized creep tensor function related to the cement paste scale. As the viscous creep function $J_{v}(t-\tau)$ is obtained for distinct times, Eq. (15) is integrated numerically by applying the trapezoidal rule.

In order to obtain the creep constants $\mu_{c, h}$ and $\beta_{h}$ related to the hydrate creep function (12) employed in the three Models 3N, 4M and 5P, the error between modelpredicted creep strains according to Eq. (15) and their experimental counterpart is minimized. In mathematical terms,

$$
\sum_{i=1}^{n_{w / c}} \sum_{j=1}^{n_{\xi}} \sum_{k=1}^{n_{t}}\left[\varepsilon_{v}^{\bmod }\left(t_{i}\right)-\varepsilon_{v}^{\exp }\left(t_{i}\right)\right]^{2} \rightarrow \min .
$$

In Eq. 16, the sum over $n_{w / c}=3$ indicates that three different cement paste mixes exhibiting $w / c \in$ $\{0.42,0.45,0.50\}$ are tested, the sum over $n_{\xi}=167$ indicates that 167 creep tests were performed on each cement composition for different maturity states, and the sum over $n_{t}=20$ indicates that 20 time values $t \in[0,3 \mathrm{~min}]$ are considered. Solving the minimization problem (16) provides model-specific optimal creep constants reading as

$$
\begin{aligned}
3 \mathrm{~N}: & \mu_{c, \mathrm{~h}}=20.9 \mathrm{GPa}, & \beta_{\mathrm{h}}=0.25, \\
4 \mathrm{M}: & \mu_{c, \mathrm{~h}}=14.9 \mathrm{GPa}, & \beta_{\mathrm{h}}=0.18, \\
5 \mathrm{P}: & \mu_{c, \mathrm{~h}}=18.1 \mathrm{GPa}, & \beta_{\mathrm{h}}=0.24 .
\end{aligned}
$$


Interestingly, the optimum hydrate shear creep modulus for models $3 \mathrm{~N}$ or $5 \mathrm{P}$ is $40 \%$ larger than for model $4 \mathrm{M}$. The microstresses in needle- or platelet-shaped hydrates (model $3 \mathrm{~N}$ or $5 \mathrm{P}$ ) are, on average, larger than the microstresses in the hydrate matrix (model 4M), leading to larger viscous strains in needle- or platelet-shaped hydrates. In order for the three models to agree with the macroscopically measured creep properties, the needleor platelet-shaped hydrates themselves need to creep less (higher shear creep modulus) than the hydrate matrix. A comparison of model realizations for hydrate creep constants from Eq. (17) with experimental data is depicted in Fig. 5.7 .
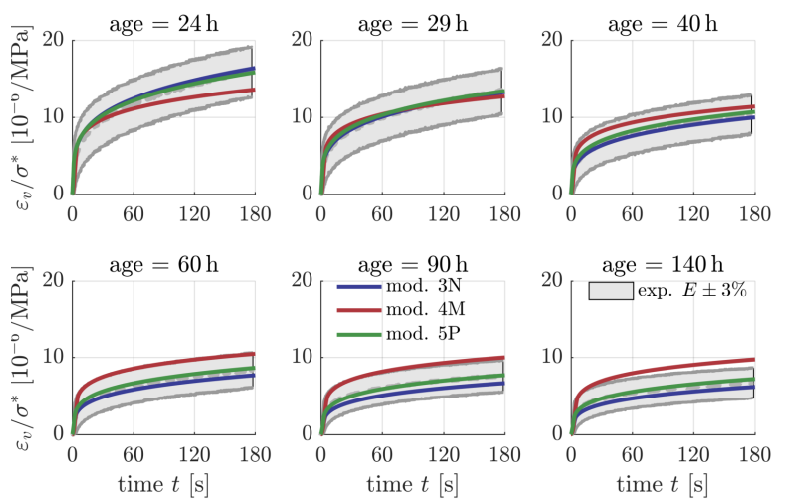

Figure 5: Model performance for Mix 1, cement paste $w / c=0.42$
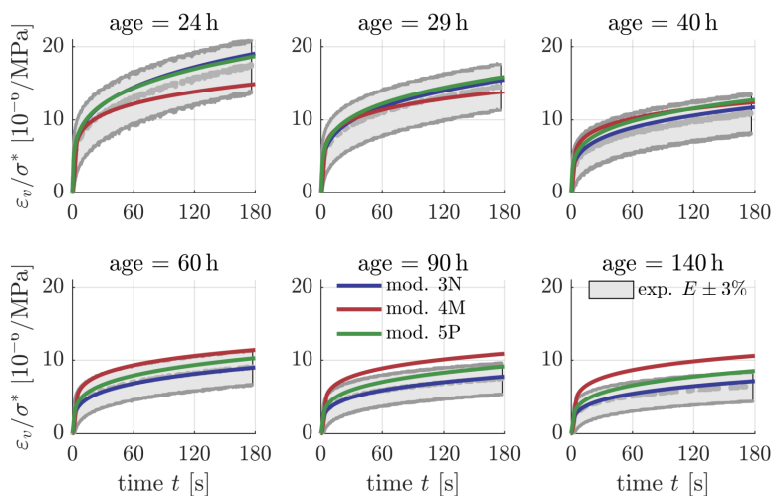

Figure 6: Model performance for Mix 2, cement paste $w / c=0.45$

Experimentally determined viscous strains are prone to errors related to imprecise measurements of the elastic modulus due to short-term creep deformations, in particular at early ages. In order to cope with these dif- 620 ficulties, we consider that the elastic modulus from experiments, denoted $E^{\exp }$, is only precise by $\pm 3 \%$. This way, we obtain an upper bound $E^{\text {up }}=1.03 E^{\exp }$ and a
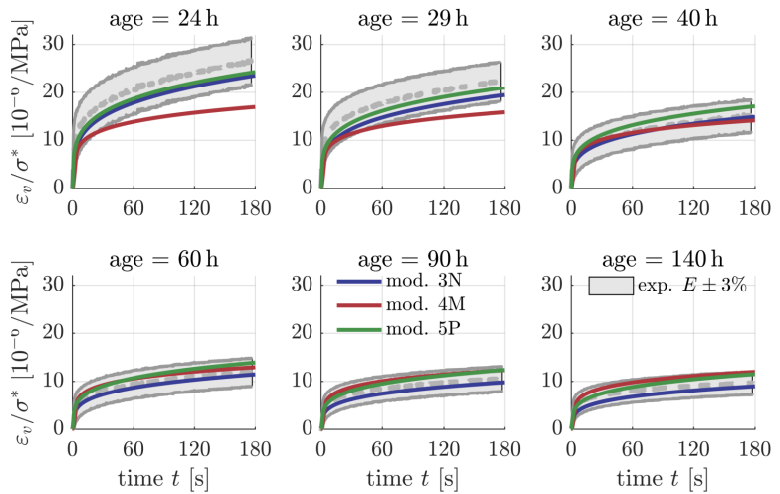

Figure 7: Model performance for Mix 3, cement paste $w / c=0.50$

lower bound $E^{\text {low }}=0.97 E^{\text {exp }}$. By analogy, we obtain upper and lower bounds for the experimental viscous strains $\varepsilon_{v}^{\exp }(t)$ by considering $E^{\mathrm{up}}$ and $E^{\text {low }}$, respectively, see the bounds of the gray areas in Figs. 5.10

\subsection{Bridging length scales: from hydrates to mortar and concrete}

Herein, we aim to validate the creep models and the identified hydrate creep constants, by comparing experimentally measured and model-predicted viscous strains $\varepsilon_{v}(t)$ during the minutes-long loading regime for mortar and concrete mixes 4-6. Model predicted strains are obtained by analogy to the procedure described in the previous section. The stress rates $\dot{\sigma}^{*}$ in the loading regime amount to $2 \mathrm{MPa} / \mathrm{s}$ for Mix 4 and 5, while for the VeRCoRs mix 6, applied stress rates increase with the age of the material, see Sec. 2.2

Model predictions for mixes 4, 5, and 6 are illustrated in Figs. 8 10 . Most of the predicted viscous strains (normalized by the plateau stresses $\sigma^{*}$ ) fall in between the intervals of the experimental data. Many model predictions are parallel to the experimentally measured evolutions. This demonstrates the characteristic accuracy with which macroscopic creep of cement paste, mortar, and concrete can be predicted based on universal C-S-H hydrate creep functions at the microscale.

While the parallelism of predictions and experiments in Figs. 8 10 underlines the performance of creep modeling, a vertical shift between the centerline of the gray experimental area and the predictions can be observed for Mixes 5 and 6, which is discussed next. For Mix 5, model predictions are situated close to the lower bound, referring to $E=0.97 E^{\exp }$. The performance for this mix can be improved based on consideration of water uptake by the open porosity of the aggregates during material production (= mixing of raw materials), 

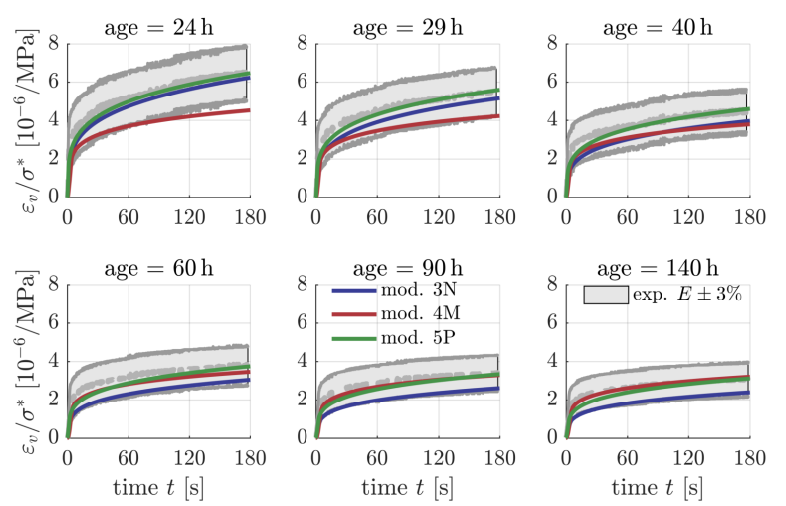

Figure 8: Model performance for Mix 4, $\operatorname{mortar} w / c=0.50$
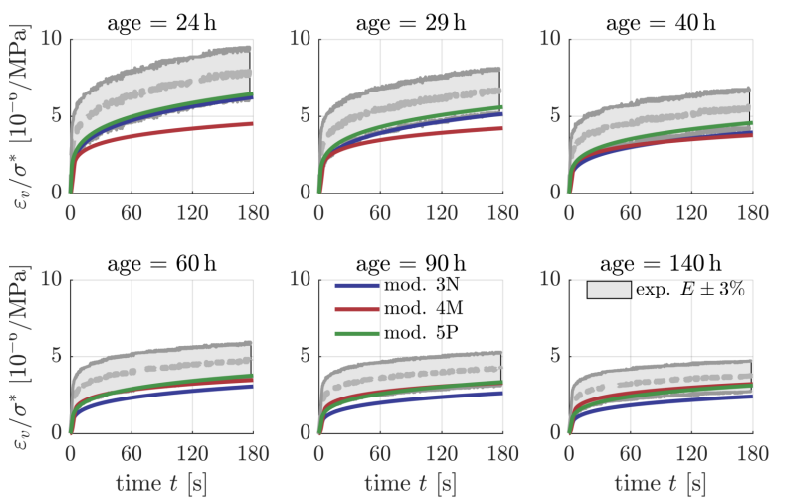

Figure 9: Model performance for Mix 5, concrete $w / c=0.50$
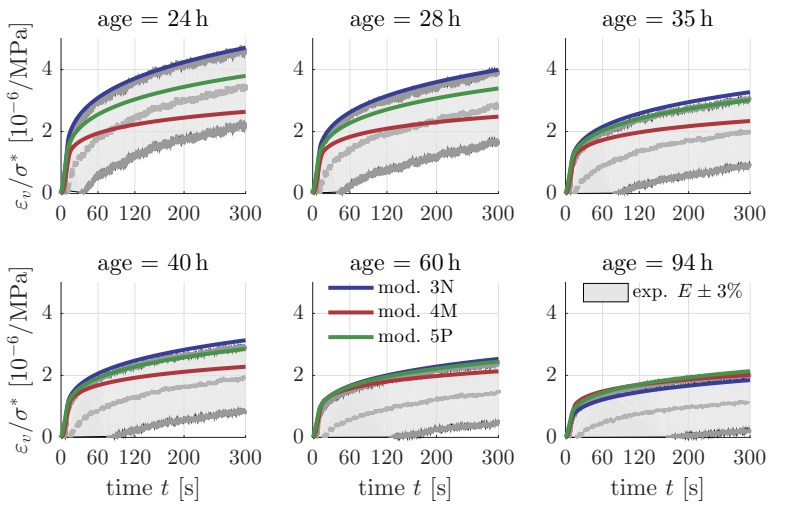

Figure 10: Model performance for Mix 6, concrete $w / c=0.52$

and slow back-suction of water to the cement paste matrix during hydration, such that the effective water-tocement mass ratio evolves during hydration, see Fig. 8 of [12]. Still, this water migration phenomenon is very slow, so that the effective water-to-cement mass ratio is virtually constant throughout every single three- 670 minutes creep test. As for Mix 6, for which the the loading/unloading moduli are used as an estimate for the elastic modulus, model predictions agree, in general, very well with the upper bound of the gray area, which corresponds to moduli increased by $3 \%$ compared to the experimentally determined loading/unloading moduli. This indicates that the actual elastic moduli might be $3 \%$ higher than the loading/unloading moduli. Notably, an underestimation of the elastic modulus does result in tensile viscous strains at the very beginning of the loading, manifesting in normalized strains below the abscissa in Fig. 10p for the centerline of the gray area which refers to $E=E^{\exp }$. Avoiding this so-called "tensile undershooting" has been the basis for separating elastic and creep strains for mixes 1-5 [11, 12], 645 and it would result in the experimental interval to shift upwards, such that the centerline comes closer to the model-predicted viscous strains.

As for quantitatively discussing the model performance, temporal evolutions of the creep strain rates, ${ }_{650} \dot{\varepsilon}_{v}\left(t, t^{\prime}\right)$, are of interest, where $t^{\prime}$ denotes the material age at the start of the creep test. Hence, we introduce the mix-specific mean relative errors $\epsilon$ as the mean of the absolute value of the difference between modeled creep strain rates and the experimentally measured creep strain rates, normalized by the mean experimental creep strain rate, reading as

$$
\epsilon=\frac{1}{n_{\text {age }} n_{t}} \sum_{j=1}^{n_{\text {age }}} \frac{\sum_{i=1}^{n_{t}}\left|\dot{\varepsilon}_{v}^{\bmod }\left(t_{i}, t_{j}^{\prime}\right)-\dot{\varepsilon}_{v}^{\exp }\left(t_{i}, t_{j}^{\prime}\right)\right|}{\frac{1}{n_{t}} \sum_{i=1}^{n_{t}} \dot{\varepsilon}_{v}^{\exp }\left(t_{i}, t_{j}^{\prime}\right)}
$$

whereby the creep strain rate evolutions are resolved for $n_{t}=200$ time steps within the last two-thirds of the load plateau and for $n_{\text {age }}=6$ ages as depicted in Figs. 5 10 . Notably, experimental creep strain rates were smoothed by means of moving averages coupled with Power-law fits in order to minimize the error related to experimental noise. Rather than model errors based on creep strains, model errors $\epsilon$ related to creep strain rates according to Eq. (18) are free of the uncertainty related the determination of the elastic modulus and therefore render a trustworthy quantity to assess the model performance.

Table 3: Model errors $\epsilon$ according to Eq. 18 in percent

\begin{tabular}{cccccccc}
\hline Model & Mix 1 & Mix 2 & Mix 3 & Mix 4 & Mix 5 & Mix 6 & Mean \\
\hline 3N & 8.8 & 8.3 & 11.9 & 25.6 & 6.5 & 12.2 & 12.2 \\
4M & 25.5 & 24.4 & 26.8 & 22.1 & 25.2 & 46.9 & 28.5 \\
5P & 12.2 & 14.2 & 25.9 & 42.4 & 14.1 & 19.2 & 21.4 \\
\hline
\end{tabular}

Comparing the model performance among the three micromechanical models, we remark that representing 
the hydrate foam as a porous polycrystal with elongated (Model 3N) or flattened (Model 5P) hydrates rather than as a porous material with a hydrate matrix ble 3 At material ages above approximately $60 \mathrm{~h}$, predicted creep strains of all three models are very close to the experimental data. At very early ages, however, the predicted creep strains of Model 4M on the basis of a C-S-H hydrates matrix are too small. We conclude that hydrate shape does matter for the prediction of creep rates at early age, for which the porosity is still high. The consideration of non-spherical hydration products is a way to enhance the accuracy of creep pre-

685 dictions for early material ages. This is in line with micromechanics-based findings from Sanahuja et al. [49], who emphasized that the shape of solid particles is a first order parameter on effective elasticity when the material's porosity is high. A similar conclusion 725 for micromechanics-based strength and elasticity predictions has been drawn from Pichler et al. [50]. Notably, local anisotropies of C-S-H in terms of C-S-H gel strands have been reported to emerge naturally in statisticial physics-based mesoscale modeling [51]. Moreover, anisotropic stiffnesses of the $\mathrm{C}-\mathrm{S}-\mathrm{H}$ nanoparticles have been found by means of molecular simulations [52], and, have then been used to successfully predict the macroscopic poro-elastic behavior of hydrating cement paste [9], again by means of incorporating non- ${ }^{730}$ spherical C-S-H shapes.

\subsection{Bridging time scales: from minute-long tests at early-age to days-long test at mature ages}

After successful upscaling from micro- or nanometersized C-S-H hydrates to centimeter-sized mortar or concrete volume elements, we herein aim time scale bridging, i.e. for model validation based on creep durations which are orders of magnitude longer than the three minutes-long creep tests on Mixes 1-3, for which the hydrate creep properties were determined. In more de-

710 tail, we aim for predicting the viscoelastic behavior of a mature cement paste tested from Tamtsia and Beaudoin [13]. The material was subjected to 30 days-long loads, 74 which is by more than four orders of magnitude longer than in the three-minutes long creep tests. All three models are therefore evaluated for the tested composition and maturity: a cement paste exhibiting $w / c=0.50$ and $\xi=0.87$ [13, 10]. The model-predicted (total) creep 750 functions for models $3 \mathrm{~N}$ and $5 \mathrm{P}$ agree very well with experimental counterpart, see Fig. 11. Predictions of Model 4M slightly overestimate the experimental results, due to the representation of the creeping hydration

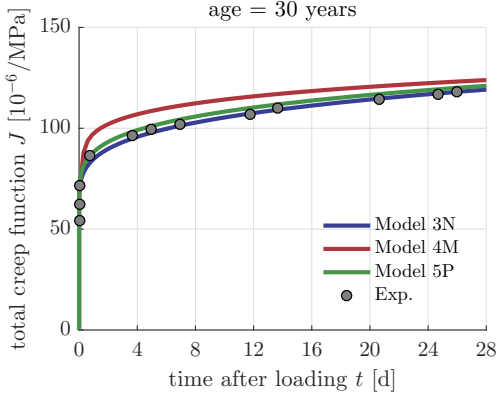

Figure 11: Model performance for long-term creep test at mature ages (Mix 7), cement paste $w / c=0.50$

products as a matrix phase. The good performance underlines that the universal hydrate creep properties are valid for predicting longer-term creep properties of mature pastes. Time scales from minutes-long creep tests at material ages of one to several days were bridged successfully to days-long creep tests at material ages of 30 years.

\subsection{Validation of elastic modulus evolutions}

While primarily focussing on the comparison of early-age creep strains, we finally compare the earlyage evolution of the macroscopic elastic moduli for Mixes 1-6. Model predicted macroscopic elastic moduli $E^{\text {mod }}$ are based on intrinsic elastic phase properties given in Table 2 and on the calorimetry-based hydration degrees coupled with the hydration models. Notably, as for Models 4M and 5P, C-S-H hydrate properties have been back-identified from the measured test results of Mixes 1-3, while Model 3N relies on literature values for the hydrate stiffnesses. Experimentally determined elastic moduli $E^{\exp }$ are again considered to be accurate by $\pm 3 \%$.

In general, model-predicted evolutions for all six mixes are very close to the experimental results, see Fig. 12 Deviations between model and experiments are typically only a few percent. Interestingly, for mortar Mix 4, measured moduli are consistently higher than the model predictions, while the modulus evolution of the concrete Mixes 5 and 6 are accurately predicted. This could be improved by adjusting sand and aggregate properties. In more detail, the modulus of the sand grains might be slightly underestimated in all models, while the modulus of the aggregates might be overestimated. 

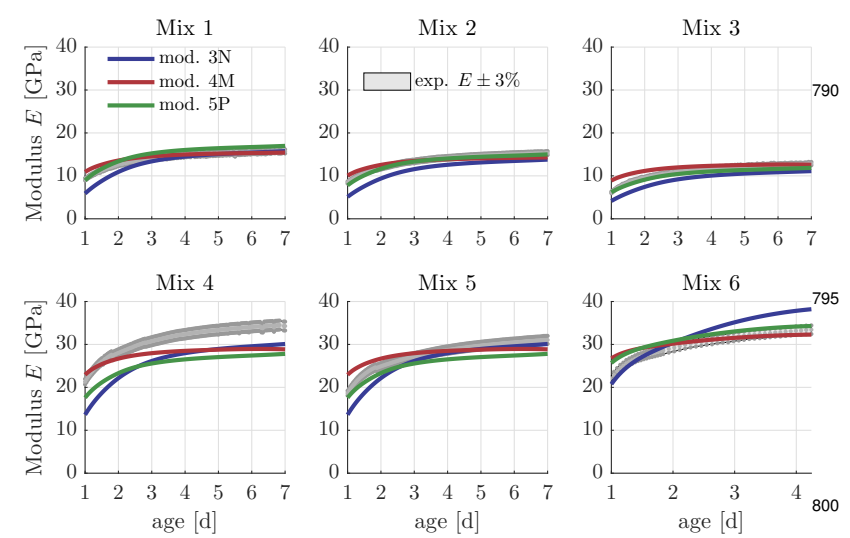

Figure 12: Model performance for early-age elastic modulus evolutions based on Mixes 1-6

\section{Discussion}

Successful length and time scale bridging provides the motivation to discuss the potentials and limitations of the micromechanics-based creep homogenization models. Particular focus is given to the character760 ization of hydrate creep, the role of the water, and the role of interfacial transition zones between aggregates and the cement paste matrix.

Experimental access to the basic creep properties of 815 hydration products such as C-S-H, the key for modeling macroscopic creep properties of cementitious materials, is still limited. Nanoindentation creep testing [53, 54, 55] has provided some insights on hydrate creep at microscopic length scales. However, the tested half- 820 spaces in nanoindentation tests are loaded heavily and deform thus elasto-plastically, i.e. the hydrates are subjected to stresses even beyond their elastic limit. As such, non-linear creep is likely to occur. Given that our benchmark scope is the prediction of basic creep, i.e. the prediction of macroscopic creep of cementitious materials subjected to stress levels which are smaller than $30 \%$ of the uniaxial compressive strength, basic hydrate creep properties would be required. In this context, Zhang et al. [56] have compared nanoindentation 830 creep tests with macroscopic creep tests and remarked that creep rates differed by one to two orders of magnitude. Only after several months to several years, macroscopic creep moduli were proportional to the contact creep moduli evaluated in minutes-long nanoindenation ${ }_{835}$ tests. As experimental techniques for identification of basic creep properties for hydrates have yet to be established, we herein rely on top-down identification based on macroscopic creep tests. This strategy continues the long tradition of identification of physical properties of 840 material constituents which are not (yet) experimentally quantified [5, 57, 10, 58].

Next, the role of water in the porous microstructure is discussed. The models consider constant, intrinsic creep properties of hydrates. This simplification limits the model to experiments with "well-saturated" hydrates. Drying processes change the hydrate creep behavior [13, 59], which is beyond the level of development of the presented models for well-saturated hydrates. Self-desiccation due to the ongoing hydration process might also change the hydrate creep behavior. For the studied pastes with $w / c \geq 0.42$, self-desiccation induced changes of the hydrate creep behavior are disregarded, since internal relative humidities for maturities of up to one week (test age for Mix 1-6) are expected to be larger than $90 \%$, as studied by Lura et al. [60] in a paste with $w / c=0.37$. Moreover, water migration between the aggregates and the hydrating cement paste, can change the effective water content in the paste, and thus the material's creep behavior. Upon mixing, water might be absorbed by the porous aggregates. Some or all of the absorbed water might then migrate back due to capillary suction, a process typically referred to as internal curing [60, 61, 62]. Herein, such transfer mechanisms are disregarded, but previous micromechanics modeling has shown that the model performance can be improved by incorporating a phenomenological model for back-suction, see [12] for details. Finally, we note that water is considered as liquid phase, thus, the solid stiffness of the all pore phases vanishes. If macroscopic loads activate pore pressures, this is to be accounted for in the context of microporomechanics [9]. Herein, however, it is assumed that capillary pores are partially saturated and connected, such that no significant capillary pore pressures develop.

In all three models, the cement paste or mortar is considered as a homogeneous matrix hosting sand grains and aggregates. Interfacial transition zones (ITZs) around the aggregates with slightly higher porosity [63], slightly lower mechanical properties [64] and therefore typically labelled as weakest links in the microstructure of concrete [65], are not considered explicitly. ITZs are well known to significantly affect the shape of the the stress-strain curve and the strength of concrete [66] due to stress concentrations around the stiff aggregates [67, 68]. As for micromechanics-based elasticity homogenization, however, neglecting the ITZs does not lead to an any significant overestimation of the concrete stiffness [69, 70, 71, 72, 73]. Thus, ITZs are herein disregarded for creep homogenization. Moreover, introduction of ITZs as additional phase in the concrete RVE would require the quantification of age-specific 
and mix-specific ITZ properties such as thickness and 890 porosity, for which experimental access is still limited.

\section{Summary and conclusions}

Three micromechanics creep models have been applied in the framework of a modeling-benchmark carried out under the umbrella of the COST Action TU1404. For each one of the used models, the creep activity of microscopic hydration products was quantified by means of downscaling results of macroscopic minutes-long creep tests performed on cement pastes at early material ages. The identified creep properties were considered to be intrinsic parts of the models, i.e. to be independent of the degree of hydration and of the mix proportions used for the production of the cementitious materials. This was the basis for predicting the creep activity of mortars and concretes at early age, as well as of cement paste at mature ages. Model predictions were compared qualitatively and quantitatively with results from experiments which were not involved in the development of the models.

From the results of the benchmark, it is concluded that creep of cement pastes, mortars, and concretes can be traced back to the specific ("intrinsic") creep behavior of microscopic calcium-silicate-hydrates. As far as modeling is concerned, this implies that creep constants 915 can be assigned to the hydrates, rather than evolving creep parameters. Once these constants are identified, the respective multiscale model can be evaluated for any specific initial composition of interest and any specific maturity of the material.

The prediction quality is related to the essential features of the microstructural representation, including the number of different observation scales, the number of different material phases, the quality of the ellipsoidal shape assigned to the material phases, and the type of envisaged phase interaction. The benchmark study suggests that the consideration of non-spherical shapes for C-S-H hydrates to represent the material's micro-anisotropy in combination with the polycrystalline microstructural representations (self-consistent homogenization scheme) yields a better model performance, as compared to $\mathrm{C}-\mathrm{S}-\mathrm{H}$ hydrates as a matrix (Mori-Tanaka homogenization scheme), in particular for highly porous microstructures as encountered at early material ages. Self-consistent homogenization including non-spherical shapes, however, is more complex to implement. Moreover, additional choices for quantifying the $\mathrm{C}-\mathrm{S}-\mathrm{H}$ phase shapes are required. As for practical applications, a trade-off must be made between the complexity of the model and the corresponding performance. In any case, all of the here-discussed multiscale models are computationally very efficient, i.e. the required computational efforts are by orders of magnitude smaller compared to what nested Finite Element resolutions of the microstructure require.

The study also underscores the importance of separating instantaneous elastic strains from time-dependent creep strains. Because the models distinguish rigorously between these two contributions to the overall deformations, it is essential for the evaluation of experiments that the same level of rigor is applied. Estimating the modulus of elasticity based on a loading modulus, or an unloading modulus, or the average of the two, has an insignificant influence on the numerical value of the modulus of elasticity, but a significant effect on the extracted creep deformation, particularly so in ultra-short creep tests which last for a few minutes only. Thus, it is essential to understand that important creep deformation develops also during short loading or unloading ramps.

\section{Acknowledgement}

The presented benchmark was carried out within a framework of activities of Work Group 2 of the COST Action TU1404 "Towards the next generation of standards for service life of cement-based materials and structures". The first author also gratefully acknowledges financial support from the Belgian National Funds for Scientific Research - FNRS.

\section{References}

[1] COST Action TU1404: Towards the next generation of standards for service life of cement-based materials and structures. http://www.tu1404.eu 2016

[2] M. Wyrzykowski, J. Sanahuja, L. Charpin, M. Königsberger, C. Hellmich, B. Pichler, L. Valentini, T. Honório, V. Smilauer, K. Hajkova, G. Ye, P. Gao, C. Dunant, A. Hilaire, S. Bishnoi, and M. Azenha. Numerical benchmark campaign of COST Action TU1404 - microstructural modelling. RILEM Tech. Lett., 2:99, 2017. doi: 10.21809/rilemtechlett.2017.44.

[3] J. Sanahuja, L. Dormieux, and G. Chanvillard. Modelling elasticity of a hydrating cement paste. Cement and Concrete Research, 37(10):1427-1439, 2007.

[4] J. Sanahuja and L. Dormieux. Creep of a C-S-H gel: a micromechanical approach. Anais da Academia Brasileira de Ciencias, 82(1):25-41, 2010.

[5] B. Pichler and C. Hellmich. Upscaling quasi-brittle strength of cement paste and mortar: A multi-scale engineering mechanics model. Cement and Concrete Research, 41(5):467-476, 2011. doi: 10.1016/j.cemconres.2011.01.010.

[6] T. Honorio, B. Bary, and F. Benboudjema. Multiscale estimation of ageing viscoelastic properties of cement-based materials: A combined analytical and numerical approach to estimate the behaviour at early age. Cement and Concrete Research, 85:137155, jul 2016. doi: 10.1016/j.cemconres.2016.03.010. 
[7] M. Königsberger, M. Hlobil, B. Delsaute, S. Staquet, C. Hellmich, and B. Pichler. Hydrate failure in itz governs concrete strength: A micro-to-macro validated engineering me- 1010 chanics model. Cement and Concrete Research, 103:77-94, jan 2018. doi: 10.1016/j.cemconres.2017.10.002.

[8] M. Königsberger and S. Staquet. Micromechanical multiscale modeling of itz-driven failure of recycled concrete: Effects of composition and maturity on the material strength. Applied Sci- 1015 ences, 8(6):976, 2018

[9] M. Königsberger, B. Pichler, and C. Hellmich. Multiscale poro-elasticity of densifying calcium-silicate hydrates in cement paste: An experimentally validated continuum micromechanics approach. International Journal of Engineering Science, 147: 1020 103196, 2020.

[10] M. Königsberger, M. Irfan-ul Hassan, B. Pichler, and C. Hellmich. Downscaling based identification of nonaging Power-law creep of cement hydrates. Journal of Engineering Mechanics, 142(12):04016106, 2016. doi: 10.1061/(ASCE) 1025 EM.1943-7889.0001169.

[11] M. Irfan-ul Hassan, B. Pichler, R. Reihsner, and C. Hellmich. Elastic and creep properties of young cement paste, as determined from hourly repeated minute-long quasi-static tests. $\mathrm{Ce}$ ment and Concrete Research, 82:36-49, 2016. doi: 10.1016/j. 1030 cemconres.2015.11.007

[12] M. Irfan-ul Hassan, M. Königsberger, R. Reihsner, C. Hellmich, and B. Pichler. How water-aggregate interactions affect concrete creep: Multiscale analysis. J. Nanomechanics Micromechanics, 7(4):04017019, dec 2017. doi: 10.1061/(asce)nm.2153-5477. 1035 0000135 .

[13] B.T. Tamtsia and J.J. Beaudoin. Basic creep of hardened cement paste: A re-examination of the role of water. Cement and Concrete Research, 30(9):1465-1475, 2000.

[14] Z.P. Bazant. Viscoelasticity of solidifying porous material- 1040 concrete. Journal of Engineering Mechanics, 103(6), 1977.

[15] M. Ausweger, E. Binder, O. Lahayne, R. Reihsner, G. Maier, M. Peyerl, and B. Pichler. Early-age evolution of strength, stiffness, and non-aging creep of concretes: Experimental characterization and correlation analysis. Materials, 12(2):207, 2019.

[16] Brice Delsaute, Claude Boulay, and Stéphanie Staquet. Creep testing of concrete since setting time by means of permanent and repeated minute-long loadings. Cem. Concr. Compos., 73:75-88, 2016. ISSN 09589465. doi: 10.1016/j.

985 cemconcomp.2016.07.005. URL http://dx.doi.org/10. 1050 1016/j.cemconcomp.2016.07.005

[17] B. Delsaute, J.-M. Torrenti, and S. Staquet. Monitoring and modeling of the early age properties of the Vercors concrete. In TINCE, page 12, sep 2016.

[18] B. Delsaute and S. Staquet. Monitoring the viscoelastic be- 105 haviour of cement based materials by means of repeated minutescale-duration loadings. In Advanced Techniques for Testing of Cement-Based Materials, pages 99-134. Springer, 2020.

[19] B. Masson and P.-M. Alliard. Objectives and design of the new experimental program VeRCoRs based on a 1/3 scaled PWR 1060 containment building. In Technical Innovation in Nuclear Civil Engineering - TINCE 2013, Paris, France, october 2013.

[20] E. Oukhemanou, S. Desforges, E. Buchoud, S. Michel-Ponnelle, and A. Courtois. VeRCoRs mock-up: Comprehensive monitoring system for reduced scale containment model. In Technical 1065 Innovation in Nuclear Civil Engineering - TINCE 2016, Paris, France, september 2016.

[21] S. Huang. Comportement vieillissant du béton en fluage : application au béton VeRCoRs. PhD thesis, ENPC, Champs sur Marne, France, december 2018.

[22] A.M.M. Neville. Properties of concrete. Pitman Publishing, London, UK, third edition, 1995.
[23] J. Carette and S. Staquet. Monitoring the setting process of mortars by ultrasonic $\mathrm{p}$ and s-wave transmission velocity measurement. Construction and Building Materials, 94:196-208, 2015.

[24] P. Karte, M. Hlobil, R. Reihsner, W. Dörner, O. Lahayne, J. Eberhardsteiner, and B. Pichler. Unloading-based stiffness characterisation of cement pastes during the second, third and fourth day after production. Strain, 51(2):156-169, 2015.

[25] B. Delsaute and S. Staquet. Development of strain-induced stresses in early age concrete composed of recycled gravel or sand. Journal of Advanced Concrete Technology, 17(6):319334, jun 2019. doi: 10.3151/jact.17.319.

[26] C. Boulay, S. Staquet, B. Delsaute, J. Carette, M. Crespini, O. Yazoghli-Marzouk, É. Merliot, and S. Ramanich. How to monitor the modulus of elasticity of concrete, automatically since the earliest age? Materials and Structures, 47(1):141$155,2014$.

[27] B. Delsaute, C. Boulay, J. Granja, J. Carette, M. Azenha, C. Dumoulin, G. Karaiskos, A. Deraemaeker, and S. Staquet. Testing concrete E-modulus at very early ages through several techniques: An inter-laboratory comparison. Strain, 52(2):91-109, 2016.

[28] B. Delsaute, J.-M. Torrenti, and S. Staquet. Modeling basic creep of concrete since setting time. cement and concrete composites, 83:239-250, 2017

[29] B.T. Tamtsia, J.J. Beaudoin, and J. Marchand. The early age short-term creep of hardening cement paste: load-induced hydration effects. Cement $\mathcal{G}$ Concrete Composites, 26(5):481-489, 2004.

[30] F. Lin and C. Meyer. Hydration kinetics modeling of Portland cement considering the effects of curing temperature and applied pressure. Cement and Concrete Research, 39(4):255-265, 2009. doi: 10.1016/j.cemconres.2009.01.014.

[31] A. Zaoui. Continuum micromechanics: Survey. Journal of Engineering Mechanics, 128(8):808-816, 2002.

[32] A.V. Hershey. The elasticity of an isotropic aggregate of anisotropic cubic crystals. Journal of Applied MechanicsTransactions, 21(3):236-240, 1954

[33] E. Kröner. Berechnung der elastischen Konstanten des Vielkristalls aus den Konstanten des Einheitskristalls [Computation of the elastic constants of a polycrystal based on the constants of the single crystal]. Zeitschrift für Physik. A: Hadrons and Nuclei, 151(4):504-518, 1958. In German.

[34] T. Mori and K. Tanaka. Average stress in matrix and average elastic energy of materials with misfitting inclusions. Acta Metallurgica, 21(5):571-574, 1973.

[35] Y. Benveniste. A new approach to the application of MoriTanaka's theory in composite materials. Mechanics of Materials, 6(2):147-157, 1987.

[36] T. Honorio, B. Bary, J. Sanahuja, and F. Benboudjema. Effective properties of $n$-coated composite spheres assemblage in an ageing linear viscoelastic framework. International Journal of Solids and Structures, 124:1-13, October 2017. ISSN 00207683. doi: 10.1016/j.ijsolstr.2017.04.028.

[37] J. Sanahuja, N.C. Tran, L. Charpin, and L. Petit. Vi (CA) 2T v2: can a concrete material properties simulation code be both physics-based and engineering-friendly. TINCE, 3:12, 2016.

[38] L. Boltzmann. Zur Theorie der elastischen Nachwirkung (concerning the theory of the elastic aftereffect). Annalen der Physik, 241(11):430-432, 1878. In German.

[39] T.C. Powers and T.L. Brownyard. Studies of the physical properties of hardened Portland cement paste. Am. Concr. Inst. J. Proc., 18(2-8):101-992, 1947-1948.

[40] T. Honorio, B. Bary, and F. Benboudjema. Thermal properties of cement-based materials: Multiscale estimations at early-age. Cement and Concrete Composites, 87:205-219, March 2018. 
ISSN 0958-9465. doi: 10.1016/j.cemconcomp.2018.01.003.

[41] T. Honorio, T. Bore, F. Benboudjema, E. Vourc'h, and M. Ferhat. Dielectric properties of the pore solution in cement-based 1140 materials. Journal of Molecular Liquids, page 112548, January 2020. ISSN 0167-7322. doi: 10.1016/j.molliq.2020.112548.

[42] T. Honorio, H. Carasek, and O. Cascudo. Electrical properties of cement-based materials: Multiscale modeling and quantification of the variability. Construction and Building Materi- 1145 als, 245:118461, June 2020. ISSN 0950-0618. doi: 10.1016/ j.conbuildmat.2020.118461.

[43] J. Sanahuja. Effective behaviour of ageing linear viscoelastic composites: Homogenization approach. International Journal of Solids and Structures, 50(19):2846-2856, September 2013. 1150 doi: 10.1016/j.ijsolstr.2013.04.023.

[44] M. Avrami. Kinetics of phase change. I. General theory. Journal of Chemical Physics, 7:1103-1112, 1939.

[45] K. Fuji and W. Kondo. Kinetics of the hydration of tricalcium silicate. Journal of the American Ceramic Society, 57:492-502, 1155 1974.

[46] J. Sanahuja, N.C. Tran, L. Charpin, and L. Petit. Material properties prediction for long term operation of nuclear power plants civil engineering structures: Challenges at EDF. IGCMAT, 1, 2016.

[47] P.D. Tennis and H.M. Jennings. A model for two types of calcium silicate hydrate in the microstructure of Portland cement pastes. Cement and Concrete Research, 30:855-863, 2000.

[48] H. Stehfest. Algorithm 368: numerical inversion of Laplace transforms. Communications of the ACM, 13(1):47-49, 1970. 1165 doi: http://doi.acm.org/10.1145/361953.361969.

[49] Julien Sanahuja, Luc Dormieux, and Gilles Chanvillard. A reply to the discussion 'does c-s-h particle shape matter?' f.-j. ulm and $h$. jennings of the paper 'modelling elasticity of a hydrating cement paste', ccr 37 (2007). Cement and Concrete Research, 1170 38(8):1130-1134, 2008

[50] B. Pichler, C. Hellmich, and J. Eberhardsteiner. Spherical and acicular representation of hydrates in a micromechanical model for cement paste: Prediction of early-age elasticity and strength Acta Mechanica, 203(3-4):137-162, 2009.

[51] K. Ioannidou, K.J. Krakowiak, M. Bauchy, C.G. Hoover, E. Masoero, S. Yip, F.-J. Ulm, P. Levitz, R.J.-M. Pellenq, and E.a Del Gado. Mesoscale texture of cement hydrates. Proceedings of the National Academy of Sciences, 113(8):2029-2034, 2016.

1115 [52] R.J.-M. Pellenq, A. Kushima, R. Shahsavari, K.J. Van Vliet, 118 M.J. Buehler, S. Yip, and F.-J. Ulm. A realistic molecular model of cement hydrates. Proceedings of the National Academy of Sciences, 106(38):16102-16107, 2009.

[53] Matthieu Vandamme and F.-J. Franz Josef Ulm. Nanogranular origin of concrete creep. Proc. Natl. Acad. Sci. U. S. A., 1061185 (26):10552-10557, jun 2009. ISSN 00278424. doi: 10.1073/ pnas.0901033106.

[54] M. Vandamme and F.-J. J. Ulm. Nanoindentation investigation of creep properties of calcium silicate hydrates. Cem. Concr. Res., 52:38-52, 2013. ISSN 00088846. doi: 10. 1190 1016/j.cemconres.2013.05.006. URL http://dx.doi.org/ 10.1016/j.cemconres.2013.05.006

[55] Hyuk Lee, Vanissorn Vimonsatit, Prinya Chindaprasirt, Tuan Ngo, and Priyan Mendis. Creep properties of cement and alkali activated fly ash materials using nanoindentation technique. 1195 Constr. Build. Mater., 168:547-555, 2018. ISSN 09500618.

n doi: 10.1016/j.conbuildmat.2018.02.166. URL https://doi. org/10.1016/j.conbuildmat.2018.02.166

[56] Qing Zhang, Robert Le Roy, Matthieu Vandamme, and Bruno Zuber. Long-term creep properties of cementitious materi- 1200 als: Comparing microindentation testing with macroscopic uniaxial compressive testing. Cem. Concr. Res., 58:89-98, apr
2014. ISSN 00088846. doi: 10.1016/j.cemconres.2014.01. 004. URL http://dx.doi.org/10.1016/j.cemconres. 2014.01.004

[57] S Ghabezloo. Micromechanics analysis of thermal expansion and thermal pressurization of a hardened cement paste. Cem. Concr. Res., 41(5):520-532, 2011.

[58] Tulio Honorio, Helena Carasek, and Oswaldo Cascudo. Electrical properties of cement-based materials: Multiscale modeling and quantification of the variability. Constr. Build. Mater, 245:118461, 2020. ISSN 09500618. doi: 10.1016/ j.conbuildmat.2020.118461. URL https://doi.org/10. 1016/j.conbuildmat.2020.118461

[59] P. Acker. Micromechanical analysis of creep and shrinkage mechanisms. In F.-J. Ulm, Z P Bažant, and F H Wittmann, editors, Creep, shrinkage Durab. Mech. Concr. other quasi-brittle Mater. 6th Int. Conf. concreep MIT, 6th International Conference CONCREEP@MIT, pages 15-26, Amsterdam, 2001. Elsevier.

[60] Pietro Lura, Ole Mejlhede Jensen, and Klaas Van Breugel. Autogenous shrinkage in high-performance cement paste: An evaluation of basic mechanisms. Cem. Concr. Res., 33(2):223-232, 2003. ISSN 00088846. doi: 10.1016/S0008-8846(02)00890-6.

[61] M Wyrzykowski, P Lura, F Pesavento, and D Gawin. Modeling of internal curing in maturing mortar. Cem. Concr. Res., 41(12): 1349-1356, 2011.

[62] J Justs, M Wyrzykowski, D Bajare, and P Lura. Internal curing by superabsorbent polymers in ultra-high performance concrete. Cem. Concr. Res., 76:82-90, 2015.

[63] J P Ollivier, J C Maso, and B Bourdette. Interfacial transition zone in concrete. Adv. Cem. Based Mater., 2(1):30-38, 1995.

[64] P. Mondal, S.P. Shah, and L.D. Marks. Nanomechanical properties of interfacial transition zone in concrete. In Z. Bittnar, P.J.M. Bartos, J. Němeček, V. Šmilauer, and J. Zeman, editors, Nanotechnology in Construction 3, pages 315-320. Springer Berlin Heidelberg, 2009.

[65] S.P. Shah and S. Chandra. Critical stress, volume change, and microcracking of concrete. American Concrete Institute Journal Proceedings, 65(9):770-780, 1968

[66] T T C Hsu, F O Slate, G M Sturman, and G Winter. Microcracking of plain concrete and the shape of the stress-strain curve. Am. Concr. Inst. J. Proc., 60(2):209-224, 1963.

[67] Markus Königsberger, Bernhard Pichler, and Christian Hellmich. Micromechanics of ITZ-aggregate interaction in concrete part I: Stress concentration. J. Am. Ceram. Soc., 97(2): 535-542, 2014. ISSN 00027820. doi: 10.1111/jace.12591.

[68] Markus Königsberger, Bernhard Pichler, and Christian Hellmich. Micromechanics of ITZ-aggregate interaction in concrete part II: Strength upscaling. J. Am. Ceram. Soc., 97(2): 543-551, 2014. ISSN 00027820. doi: 10.1111/jace.12591.

[69] P. Simeonov and S. Ahmad. Effect of transition zone on the elastic behavior of cement-based composites. Cement and Concrete Research, 25(1):165-176, 1995.

[70] A.U. Nilsen and P.J.M. Monteiro. Concrete: A three phase material. Cement and Concrete Research, 23(1):147-151, 1993.

[71] M.P. Lutz, P.J.M. Monteiro, and R.W. Zimmerman. Inhomogeneous interfacial transition zone model for the bulk modulus of mortar. Cement and Concrete Research, 27(7):1113-1122, 1997.

[72] G. Ramesh, E.D. Sotelino, and W.-F. Chen. Effect of transition zone on elastic moduli of concrete materials. Cement and Concrete Research, 26(4):611-622, 1996.

[73] C.C. Yang and R. Huang. Double inclusion model for approximate elastic moduli of concrete material. Cement and Concrete Research, 26(1):83-91, 1996. 